\title{
Stroke care equity in rural and remote areas - novel strategies
}

\author{
Silke Walter ${ }^{1}$, Klaus Fassbender ${ }^{1}$, Damien Easton ${ }^{2}$, Madeleine Schwarz ${ }^{1}$, Fergus W. Gardiner ${ }^{3,4}$, Francesca \\ Langenberg ${ }^{2}$, Angela Dos Santos ${ }^{2}$, Cees $\mathrm{Bil}^{5}$, Kate Fox ${ }^{5}$, Lara Bishop ${ }^{3,4}$, Skye Coote ${ }^{2}$, Henry Zhao ${ }^{2}$, Sandy \\ Middleton $^{6}$, Christopher Bladin ${ }^{7}$, Stephen M. Davis ${ }^{2, \#}$, Geoffrey A. Donnan ${ }^{2, \#}$ \\ 'Department of Neurology, Saarland University, Homburg 66421, Germany. \\ ${ }^{2}$ Melbourne Brain Centre, University of Melbourne, Melbourne 3050, Australia. \\ ${ }^{3}$ The Royal Flying Doctor Service, Kingston ACT 2604, Australia. \\ ${ }^{4}$ National Centre for Epidemiology and Population Health, Research School of Population Health, The Australian National \\ University, Canberra 0200, Australia. \\ ${ }^{5}$ Department of Aerospace Engineering, RMIT University, Melbourne 3001 Australia. \\ ${ }^{6}$ Australian Catholic University, Sydney 2001, Australia. \\ ${ }^{7}$ Ambulance Victoria, and Monash University Melbourne 3800, Australia. \\ ${ }^{\#}$ Authors contributed equally, joint senior authors.
}

Correspondence to: Prof. Geoffrey A. Donnan, Melbourne Brain Centre, Royal Melbourne Hospital, 4/300 Grattan St, Parkville VIC 3050, Australia. E-mail: geoffrey.donnan@unimelb.edu.au

How to cite this article: Walter S, Fassbender K, Easton D, Schwarz M, Gardiner FW, Langenberg F, Santos AD, Bil C, Fox K, Bishop L, Coote S, Zhao H, Middleton S, Bladin C, Davis SM, Donnan GA. Stroke care equity in rural and remote areas - novel strategies. Vessel Plus 2021;5:27. https://dx.doi.org/10.20517/2574-1209.2020.102

Received: 24 Dec 2020 First Decision: 18 Jan 2021 Revised: 3 Feb 2021 Accepted: 8 Feb 2021 Published: 17 May 2021

Academic Editor: Aaron S. Dumont Copy Editor: Xi-Jun Chen Production Editor: Xi-Jun Chen

\begin{abstract}
Acute stroke is one of the most common causes of disability worldwide and numbers are projected to increase. Modern and successful recanalizing treatments are available, but timely access to these treatments is most often restricted to urban populations. This disparity affects nearly half of the world's population, particularly those living in rural and remote areas, and most often affects people with indigenous background. We provide information on this disparity in acute stroke care between rural, remote, and urban areas. We discuss potential new management strategies which could facilitate the timely delivery of acute stroke care to those residents beyond the better serviced urban areas. We focus on the concept of a mobile stroke unit (MSU), especially an Air-MSU. This aircraft solution could provide an imaging capability and immediate clinical expertise via linked telemedicine to diagnose and treat acute stroke patients at the emergency site. The Air-MSU is not only envisioned to allow intravenous thrombolysis in the field but also to allow pre-hospital triage to comprehensive stroke centres through use of contrast imaging to diagnose large vessel occlusion, facilitating endovascular thrombectomy. Moreover, issues regarding optimal operating environment as well as novel imaging and diagnostic devices, which could facilitate the
\end{abstract}


implementation of an Air-MSU are discussed. Innovative health care solutions are urgently needed to close the treatment gap for stroke patients living in rural and remote regions worldwide.

Keywords: Air-MSU, remote areas, stroke treatment, pre-hospital stroke management, stroke thrombolysis, thrombectomy

\section{INTRODUCTION}

\section{Stroke and global effects}

Stroke is the second most common cause of death and accounts for $12 \%$ of all deaths worldwide. Projections by World Health Organisation for 2016 to 2060 do not predict any improvement. While some areas of the world, such as America and Europe, might see a drop in their numbers, others, like Africa and Western Pacific regions are expected to face an increase in stroke deaths ${ }^{[1]}$.

Currently, there are approximately 80 million stroke survivors globally, and due to population growth and aging, this number is predicted to increase dramatically. Stroke is the leading contributor (42.2\%) to disability-adjusted life-years, which is the sum of years of life lost and years lived with disability. This number is also predicted to increase $\mathrm{e}^{[2]}$.

Despite significant advances in new therapies to treat stroke, one of the most important challenges in stroke management today is the delivery of these therapies to rural and remote areas. Access to the most effective therapies, thrombolysis or thrombectomy, for patients with acute ischaemic stroke has become a "postcode lottery." In other words, the geographical location of residence defines the available access to acute stroke, leading to an unacceptable inequity of opportunity. This applies not only to developing nations, but also to some of the wealthiest countries. Even in well-resourced regions, there are surprising problems in health care delivery and equitably to all people regardless of location. It is important to recognize that $44 \%$ of the world's population lives in rural and remote areas with only limited access to high-quality stroke care ${ }^{[3]}$. This is often most markedly affecting those of indigenous background ${ }^{[4,5]}$.

\section{Where you live defines what you get}

Delivery of the three major evidence-based acute ischaemic stroke treatments, which strongly influence mortality and disability - treatment on a stroke unit, thrombolysis in ischaemic stroke, and endovascular thrombectomy for those with large vessel occlusion - is challenging in areas with a low population density. It is known that the distance to the nearest stroke centre is a crucial factor for delivery of timely stroke treatment ${ }^{[6,7]}$. Reported times from symptom onset to admission to rural hospitals range from 5-30 $\mathrm{h}^{[8,9]}$. These pre-hospital delays have subsequently been attributed as a major driver of the very low thrombolysis rates of only $1 \%-6 \%$ for patients in rural areas worldwide ${ }^{[10-12]}$. This contrasts with rates of $20 \%-25 \%$ in metropolitan stroke centres. The decisions about the type of care and how access to acute care will be achieved is most often dominated by the question of cost efficiency rather than need. The reality is that patient numbers in these rural and remote areas are often too low to enable an economically viable service. This, together with the view that the individual preference and decision to live in rural/remote areas should not increase health care costs of the whole society, impedes process improvement.

The quality of acute stroke management varies between countries, but interestingly, also within regions of individual countries. This not only applies to middle- or low-income countries, which lack the financial resources to establish high-quality care for what is, in reality, only a few people, but also to high income countries. 
Good examples of this are Australia and Canada, both high-income nations with the lowest population density globally ( 3 and 4 inhabitants $/ \mathrm{km}^{2}$ respectively). In Australia, only $3 \%$ of the acute stroke patients in rural regions are able to access a stroke unit compared to around $70 \%$ in urban regions, many of them travelling over $200 \mathrm{~km}$ to reach a hospital with adequate stroke care ${ }^{[13,14]}$. Further, the majority of patients living in rural areas world-wide are less likely to receive brain imaging within $24 \mathrm{~h}$, carotid imaging, or consultation with a stroke physician. In Australia, most emergency retrievals are performed by the Australian Royal Flying Doctor Service (RFDS), the largest such aeromedical retrieval service world-wide, with a fleet of almost 80 aircraft. In a recent study, it was found that most retrieval locations lacked brain imaging capability, significantly delaying stroke diagnosis and treatment ${ }^{[15]}$. An unpublished analysis of access to radiological imaging in Australia shows that hospitals with computed tomography (CT) scanners are mainly located in the south-eastern coastal areas [Figure 1], leaving many areas lacking service. The lack of imaging availability in rural and remote areas directly translates to a lower number of patients receiving the modern, time sensitive stroke interventions enjoyed by urban Australians. This paucity of service intervention is particularly important in the case of endovascular treatment, one of the most effective interventions in modern medicine, which can only be performed at highly specialised stroke centres ${ }^{[16]}$. Most of these comprehensive stroke centres are located in metropolitan centres ${ }^{[17]}$.

In Canada, the numbers are similar where $20 \%$ of the Canadian population lives in rural areas ${ }^{[18]}$. Only $11 \%$ of the rural hospitals in Canada are equipped with a CT scanner, and 40\% of these rural hospitals are more than $300 \mathrm{~km}$ from a comprehensive stroke centre. Access to acute stroke service strongly depends on the area of stroke incidence. A recent geospatial analysis has shown that in some areas, such as Saskatchewan, Newfoundland, and Labrador, less than half of the population could reach a stroke centre within $3.5 \mathrm{~h}$ with emergency transport ${ }^{[19]}$. Not surprisingly, the 30-day stroke mortality is higher for patients treated in rural compared to urban hospitals ${ }^{[20,21]}$.

This geographical inequity in acute stroke care is not a problem which is likely to improve in the near future. A recent analysis of the rural vs. urban disparity in stroke thrombolysis, including 914,500 acute ischaemic stroke patients in the USA, revealed that geographic disparity in alteplase use is actually increasing $^{[22]}$. This emphasises the need to narrow this unacceptable gap with novel disease management ideas and strategies. While the strategies suggested in this review are being, or more likely to be, implemented in developed nations, the lessons learned may become quite relevant for developing nations.

\section{MOBILE STROKE UNITS - A HYPERACUTE SOLUTION FOR HYPERACUTE STROKE TREATMENT}

Mobile stroke units (MSU) are acute specialist ambulances, equipped with computed tomography (CT) scanners, point-of-care laboratory units, and telemedicine capabilities for interaction with experts in the hospital. They have been implemented to enable immediate diagnosis and administration of thrombolysis for eligible stroke patients directly at the emergency site ${ }^{[23,24]}$. In many countries, pre-hospital stroke diagnosis and treatment have validated this MSU concept. Randomised studies have shown that MSU-based stroke management can reduce the time to treatment and substantially increase the number of treated patients. More importantly, golden hour thrombolysis, namely treatment within the first $60 \mathrm{~min}$ after symptom onset, with highest chances of full recovery, is far more commonly achieved in the MSU group compared to the control group ${ }^{[25-27]}$. Indeed, a recent prospective interventional study (B-Proud) with acute ischaemic stroke patients showed that the dispatch of a MSU was significantly associated with a better clinical outcome as assessed with the modified Ranking score after 90 days ${ }^{[28]}$. 


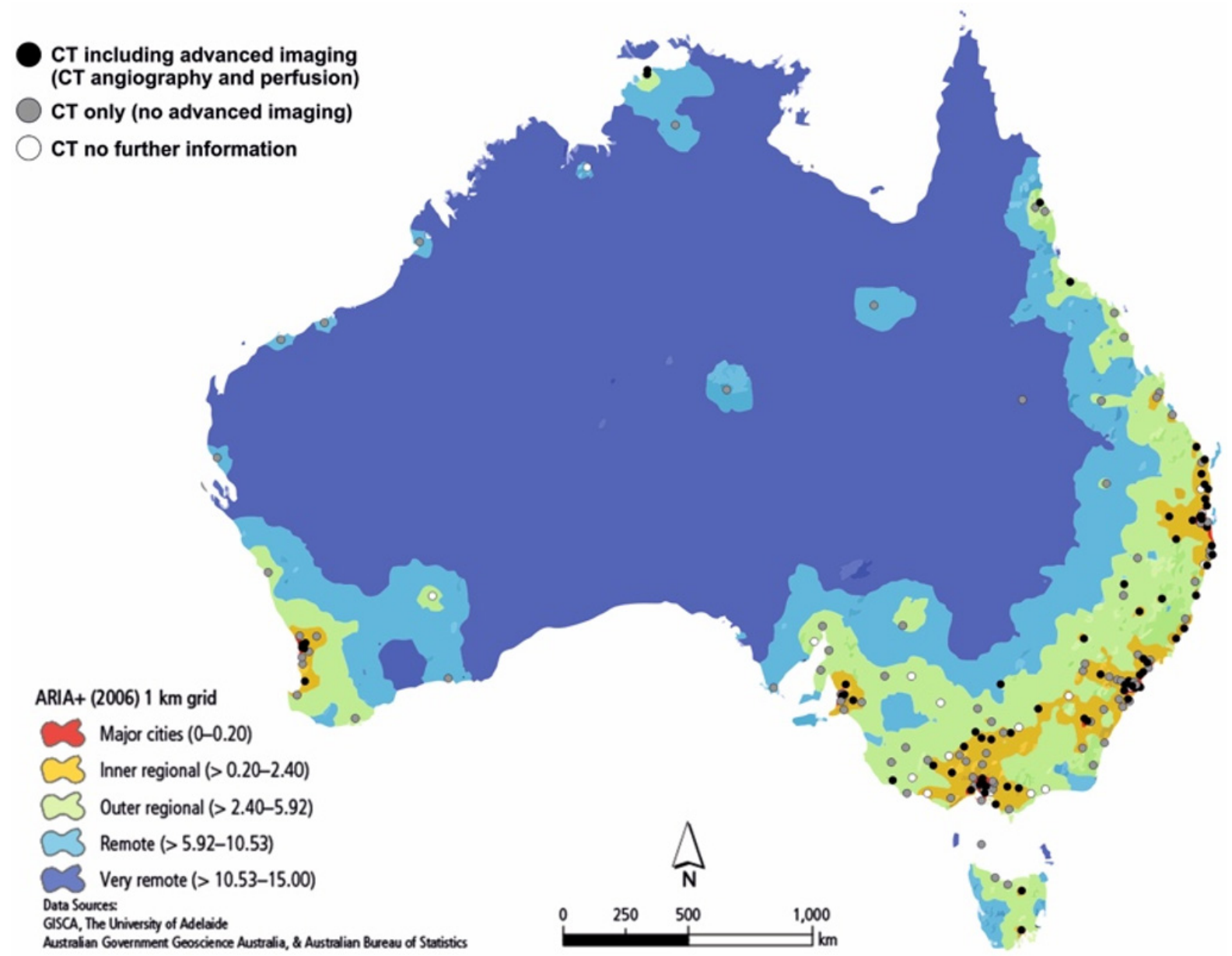

Figure 1. Example of access to stroke imaging in Australia. Hospitals with multi-modal computed tomography (CT) imaging availability are indicated by black circles. Grey circles represent hospitals with non-contrast CT scans possibility only. Imaging is mainly available in the area of higher population density in the south east of the country.

In addition, with the possibility to perform a CT angiography directly at the emergency site, MSUs have the potential for diagnosis-based triage decision-making at the emergency site ${ }^{[25,29]}$. Correct triage allows patients to be delivered much faster to centres where catheter-based treatment for thrombectomy for large vessel occlusion can be carried out. This can positively impact their clinical outcome.

\section{DEVELOPMENT OF AN AIR-MSU - A POTENTIAL SOLUTION FOR RURAL AND REMOTE STROKE TREATMENT ACCESS?}

The concept of using a MSU for stroke assessment with optimised triage and treatment initiation at the emergency site could represent a novel acute stroke management strategy for rural and remote areas. The concept would need adjustment for these areas to match the need for a timely access to hyperacute care. The implementation of the MSU concept in an aircraft might represent an alternative way to deliver acute stroke care to underserviced areas.

As an extension of the specialist care the RFDS delivers in Australia, discussions about an Air-MSU have evolved recently ${ }^{[30]}$. The concept involves an airplane or helicopter Air-MSU equipped identically to a MSU road ambulance with multimodal imaging capabilities, a point-of-care laboratory, and a telemedicine 
connection to a stroke specialised centre so that stroke patients in remote regions could obtain diagnosis and treatment at the emergency site. The large Victorian Stroke Telemedicine project, a state-wide programme to establish access to acute stroke thrombolysis in non-specialised regional hospitals has demonstrated that the delivery of acute remote stroke specialist support can be safely implemented ${ }^{[31]}$.

The advantage of a helicopter solution is the potential for rapid activation (no runway needed) and the direct landing possibilities on hospital helipads. A fixed-wing aircraft, however, would be able to cover a much wider area of approximately $5000 \mathrm{~km}$ in radius with a shorter flying time.

There are different settings in which such an Air-MSU could be beneficial and it can be assumed that the daily operation of such an Air-MSU would need to have a high level of flexibility, mainly because constant changes are likely to occur in the setting depending on the actual emergency call and situation on scene. An Air-MSU could be used in a similar way to a road MSU as a first responding ambulance directly dispatched to the patient. The team would then function as first emergency medical team for the patient, independent of the actual medical condition. The disadvantage of this arrangement is that the crew is then locked into the current event and therefore might not be available for other even more deserving calls. For example, a stroke patient who may be suitable for early therapeutic intervention appears while the current call turns out to be a stroke-mimic.

Alternatively, the Air-MSU could operate in a rendezvous system and meet the patients en-route once a first local emergency medical service crew has clinically confirmed the stroke diagnosis. This setting is dependent on the availability of the local emergency medical service and might vary from day to day. The advantage is not only that the diagnosis accuracy of the stroke call is higher for the Air-MSU team but also that there would be additional help available to manage a difficult scene.

In both scenarios an acute stroke treatment with intravenous thrombolysis, could be initiated at the emergency site, saving crucial time for the patient.

A third scenario would be an inter-hospital transfer of patients from local hospitals/health care centres to stroke specialised centres. A recent publication of the RFDS stroke retrieval calls in rural Australia describes more than 1700 retrieval flights for acute stroke patients in a period of 4 years with a median flight distance of $291 \mathrm{~km}$ per patient and a median transfer time of $238 \mathrm{~min}$. The subtype of the stroke was not categorised for most of these patients as CT scanners were not available ${ }^{[32]}$ so that a specific therapy such as intravenous thrombolysis could not be started. Most of these transfers were time consuming with an attendant delay such that patients were usually outside their treatment time window once arriving at the stroke centre ${ }^{[15]}$. In this situation, the Air-MSU could provide immediate stroke diagnostic assessment and treatment initiation before transferring the patient to the required level of stroke care.

However, all these scenarios depend on an accurate direct dispatch of the Air-MSU and the first team involved to develop a likely working diagnosis of an acute stroke including treatment eligibility. This is one of the significant hurdles in the delivery of acute stroke care, as well as in standard stroke management. Inappropriate activation of a specialised stroke team reduces its targeted capacity for those likely to benefit. This is even more relevant when the specialised stroke team has long distances to travel for patient retrieval as would be the case with an Air-MSU approach. Hence, an appropriate implementation of such a novel system of care would require an optimised pathway to identify relevant patients. This would include an embedded, country- and region-specific education programme, not only for the dispatch centres, but also for the local emergency medical service, healthcare centres and every other link in the chain. Specialised 
training may include the implementation of specific stroke dispatch criteria, dispatch call monitoring ${ }^{[33]}$, telemedicine to triage cases prior to activation and use of more accurate stroke scales ${ }^{[34]}$. The challenge should ideally be nation-wide and involve government with initiatives such as "calling stroke a national priority"[35].

Another main hurdle in the implementation of an Air-MSU for acute stroke care in geographically large, underserviced areas is the significant development necessary to integrate a CT scanner on board a flying ambulance. Alternate imaging devices for diagnosis and differentiation of the different stroke subtypes should, therefore, be considered and may be equally advantageous in acute stroke management.

\section{ALTERNATIVE STROKE ASSESSMENT OPTIONS - AN ALTERNATIVE TO A CT SCANNER}

In recent years intensive research has been undertaken to investigate new, lightweight, portable, and affordable devices with the aim of making a fast and accurate on-site diagnosis. Pilot protypes of devices being currently developed aim to reduce weight from around $500 \mathrm{~kg}$ to 50-100 kg. Many of these are newly developed imaging devices with a focus on identification of intracranial changes after brain trauma, such as subdural haematoma or deterioration due to brain edema hours to days after stroke symptom onset, when structural changes are more easily detectable ${ }^{[36]}$. Only few devices have been developed which have the potential to differentiate ischaemic $v s$. haemorrhagic strokes within the first hour after symptom onset. This differentiation is the most critical goal, given that administration of thrombolysis could be catastrophic in intracerebral haemorrhage. One of these is using a microwave technique, which can detect changes in the electrical properties of brain tissue due to change in blood flow, water content, and temperature with a high sensitivity. In early clinical tests, the ability of microwaves to differentiate haemorrhagic stroke from ischaemic stroke was described with an area under the curve of $0.85-0.88^{[37]}$. Further research is necessary to increase the understanding and the potential area of usage for this novel diagnostic strategy and as to whether the sensitivity and specificity are high enough for clinicians to confidently exclude the presence of blood to enable thrombolysis remains to be seen.

The CT scanner currently used in most mobile stroke units weighs at least $500 \mathrm{~kg}$. There is the potential for the development of light-weight portable CT scanners using novel, non-thermionic nanotube technology. This allows miniaturization of the scanner and has no moving parts. This is another exciting research avenue for road and air transport platforms, to serve rural and remote populations ${ }^{[38]}$.

It is well known that intracranial large vessel occlusions can be visualized with a transcranial ultrasound technique ${ }^{[39]}$. Special ultrasound devices combining artificial intelligence, robotics, and automated cerebral ultrasound are under development to enable an operator-independent tool to identify acute stroke ${ }^{[40]}$. Mobile transcranial ultrasound has been shown to identify an acute anterior large vessel occlusion stroke with a sensitivity of $78 \%$ and specificity of $98 \%{ }^{[41]}$.

Specific biomarker analysis is an alternative point-of-care blood test, which could be an ideal tool for a prehospital stroke assessment. The STROKECheck device uses the identification of the biomarkers GFAP, RBP-4, and NT-proBNP to differentiate ischaemic stroke including large vessel occlusion from haemorrhagic strokes and stroke mimics. The device is currently being investigated in a pre-hospital trial (Biomarkers for Initiating Onsite and Faster Ambulance Stroke Therapies, Bio-FAST, ClinicalTrials.gov Identifier: NCT04612218) in southern Europe. First results of 90 participants showed that $84 \%$ of ischaemic stroke patients could be identified with the biomarker device without incorrect identification of intracerebral haemorrhage ${ }^{[42]}$. Table 1 gives a summary of the above mentioned novel diagnostic tool with available evidence and ongoing clinical trials. 
Table 1. Novel stroke diagnostic tools for stroke diagnosis in the hyperacute phase

\begin{tabular}{|c|c|c|c|c|}
\hline Device & Mode of action/aim & Evidence & Pro/Cons & Ref. \\
\hline Lightweight CT scanner & $\begin{array}{l}\text { - Non-thermionic nanotube } \\
\text { technology } \\
\text { - Differentiation of ischaemic vs. } \\
\text { haemorrhagic stroke vs. stroke } \\
\text { mimic }\end{array}$ & - No clinical data available & $\begin{array}{l}\text { - Detection of other } \\
\text { brain diseases } \\
\text { possible } \\
\text { - May be able to } \\
\text { include perfusion } \\
\text { imaging } \\
\text { - Possibly more } \\
\text { expensive }\end{array}$ & {$[38]$} \\
\hline Microwave technique & $\begin{array}{l}\text { - Detects dielectric contrast } \\
\text { between tissues (in stroke: } \\
\text { contrast between blood and } \\
\text { grey and white matter) } \\
\text { - Differentiation of ischaemic vs. } \\
\text { haemorrhagic stroke }\end{array}$ & $\begin{array}{l}\text { - Early clinical studies: area under the curve of 0.85-0.88 } \\
\text { - Phase II/III trial: "Mobile Microwave-based Diagnosis and Monitoring of Stroke: on } \\
\text { the Road Towards Improved Stroke Triage and Care, Including Prehospital Initiation of } \\
\text { Thrombolytic Treatment," currently recruiting, completion expected Feb } 2022\end{array}$ & $\begin{array}{l}\text { - Identification of } \\
\text { stroke mimicking } \\
\text { diseases not possible } \\
\text { - Low cost } \\
\text { - No perfusion } \\
\text { imaging }\end{array}$ & $\begin{array}{l}{[37]} \\
\text { MODS trial: ClinicalTrials.gov } \\
\text { Identifier: NCT04257149 }\end{array}$ \\
\hline $\begin{array}{l}\text { Mobile transcranial } \\
\text { ultrasound including robotics } \\
\text { and artificial intelligence }\end{array}$ & $\begin{array}{l}\text { - Ultrasound detection of } \\
\text { occlusion signal } \\
\text { - Differentiation of large vessel } \\
\text { occlusion ischaemic stroke }\end{array}$ & - Sensitivity of $78 \%$ and specificity of $98 \%$ & $\begin{array}{l}\text { - No stand-alone } \\
\text { diagnostic tool }\end{array}$ & [40-41] \\
\hline \multirow{4}{*}{$\begin{array}{l}\text { Blood biomarker: glial } \\
\text { fibrillary acidic protein } \\
\text { (GFAP), retinol binding } \\
\text { protein (RBP-4) and NT- } \\
\text { proBNP }\end{array}$} & \multirow{4}{*}{$\begin{array}{l}\text { - Blood point of care test } \\
\text { - Differentiation of ischaemic vs. } \\
\text { haemorrhagic stroke (vs. stroke } \\
\text { mimic) }\end{array}$} & $\begin{array}{l}\text { - First results STROKECheck device (GFAP, RBP-4, NT-proBNP), Bio-FAST trial): } 84 \% \\
\text { of ischaemic stroke patients could be identified }\end{array}$ & \multirow[t]{4}{*}{$\begin{array}{l}\text { - Accuracy in early } \\
\text { hours after symptom } \\
\text { onset unclear }\end{array}$} & $\begin{array}{l}\text { [42] } \\
\text { Bio-FAST trial: ClinicalTrials.gov } \\
\text { Identifier: NCT04612218 }\end{array}$ \\
\hline & & 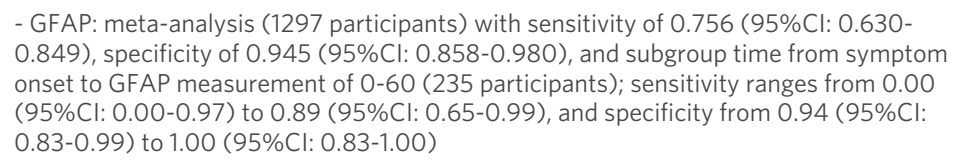 & & {$[43]$} \\
\hline & & $\begin{array}{l}\text { - GFAP + RBP-4: patients with ICH who had RBP4 }<48.75 \text { microg } / \mathrm{mL} \text { and GFAP }> \\
0.07 \mathrm{ng} / \mathrm{mL} \text { : sensitivity }=32 \% \text {, specificity }=100 \%\end{array}$ & & {$[44]$} \\
\hline & & $\begin{array}{l}\text { - Open label non-randomised, prospective, pre-hospital trial: "Prehospital Advanced } \\
\text { Diagnostics and Treatment of Acute Stroke" to define cut-off values for GFAP and } \\
\text { RBP4 }\end{array}$ & & $\begin{array}{l}\text { Treat-NASPP: ClinicalTrials.gov } \\
\text { Identifier: } \\
\text { NCT03158259Formularende }\end{array}$ \\
\hline
\end{tabular}

MODS: Mobile Microwave-based Diagnosis and Monitoring of Stroke: on the Road Towards Improved Stroke Triage and Care, Including Prehospital Initiation of Thrombolytic Treatment; GFAP: glial fibrillary acidic protein; RBP-4: retinol binding protein; NT-proBNP: N-terminal pro B-type natriuretic peptide; Treat-NASPP: Prehospital Advanced Diagnostics and Treatment of Acute Stroke.

If alternative therapeutic devices shall find a place in acute stroke diagnosis in future, it is likely that several different technologies will need to be combined to allow a more precise diagnosis. However, all of these devices are likely to be small and light enough to be easily transported to acute stroke patients in rural and remote areas, enabling faster diagnosis and timely initiation of treatment. 


\section{CONCLUSION}

Patients with stroke in rural and remote areas around the world have an unacceptable inequity in access to acute treatment compared to their urban counterparts. New approaches are urgently needed to overcome this service delivery gap. The concept of an Air-MSU "bringing the stroke treatment to the patient" and linked to telemedicine services may be a novel solution to allow diagnosis of stroke patients at the emergency site. This is likely to facilitate faster triage and initiation of acute stroke treatment. The mobility and flexibility of the Air-MSU concept may present a superior strategy to the more obvious and traditional approach of overcoming tyranny of distance by establishing more on-site stroke capable health care facilities. The development of novel diagnostic imaging and diagnostic tools may help reduce the cost of implementation of an Air-MSU service. While early implementation is more likely in developed countries, and further research is needed to understand the optimal technical and clinical settings, lessons learned may later become important for developing nations. Also, careful cost benefit analysis for the individual settings will be needed, which not only addresses the overall benefits but also the question of availability of resources, costs of implementation, and financial sustainability, which are crucial factors for most countries worldwide.

\section{DECLARATIONS}

\section{Authors' contributions}

Wrote drafts of the manuscript, conceptualized ideas, provided inputs for all aspects of the manuscript preparation and of the scientific content and reviewed the manuscript: Walter S, Easton D, Schwarz M, Zhao H, Davis SM, Donnan GA

Conceptualized ideas, edited and critically reviewed and discussed the manuscript: Fassbender K, Gardiner FW, Langenberg F, Dos Santos A, Bil C, Fox K, Bishop L, Coote S, Middleton S, Bladin C

\section{Availability of data and materials}

Not applicable.

\section{Financial support and sponsorship}

None.

\section{Conflicts of interest}

All authors declared that there are no conflicts of interest.

\section{Ethical approval and consent to participate}

Not applicable.

\section{Consent for publication}

Not applicable.

\section{Copyright}

(c) The Author(s) 2021.

\section{REFERENCES}

1. World Health Organisation. Global Health Estimates. Projections of mortality and causes of death, 2016 to 2060 ; October 2018. https://www.who.int/healthinfo/global_burden_disease/projections/en/have. [Last accessed on 23 Feb 2021].

2. 2016 Stroke Collaborator. Global, regional, and national burden of stroke, 1990-2016: a systematic analysis for the Global Burden of Disease Study 2016. Lancet Neurol 2019;18:439-58. DOI PubMed PMC

3. United Nations, Population Division of the Department of Economic and Social Affairs (UN DESA). 2018 Revision of the World Urbanization Prospects. Available from: https:/www.un.org/development/desa/publications/2018-revision-of-world-urbanizationprospects.html. [Last accessed on 23 Feb 2021].

4. Anand SS, Abonyi S, Arbour L, et al. , Canadian Alliance for Healthy Hearts and Minds First Nations Research Group. Explaining the 
variability in cardiovascular risk factors among First Nations communities in Canada: a population-based study. Lancet Planet Health 2019;3:e511-20. DOI PubMed

5. Tiedeman C, Suthers B, Julien B, Hackett A, Oakley P. Management of stroke in the Australian Indigenous population: from hospitals to communities. Intern Med J 2019;49:962-8. DOI PubMed

6. Cox AM, Mckevitt C, Rudd AG, Wolfe CD. Socioeconomic status and stroke. Lancet Neurology 2006;5:181-8. DOI PubMed

7. Teuschl Y, Brainin M. Stroke education: discrepancies among factors influencing prehospital delay and stroke knowledge. Int J Stroke 2010;5:187-208. DOI PubMed

8. Joubert J, Prentice LF, Moulin T, et al. Stroke in rural areas and small communities. Stroke 2008;39:1920-8. DOI PubMed

9. Oliveira-Filho J, Martins SC, Pontes-Neto OM, et al; Executive Committee from Brazilian Stroke Society and the Scientific Department in Cerebrovascular Diseases. Guidelines for acute ischemic stroke treatment: part I. Arq Neuropsiquiatr 2012;70:621-9. DOI PubMed

10. Newbury J, Kleinig T, Leyden J, et al. Stroke Epidemiology in an Australian Rural Cohort (SEARCH). Int J Stroke 2017;12:161-8. DOI PubMed

11. Ganesh A, Camden M, Lindsay P, et al; Canadian Stroke Audit Group. The quality of treatment of hyperacute ischemic stroke in Canada: a retrospective chart audit. CMAJ Open 2014;2:E233-9. DOI PubMed PMC

12. Cadilhac DA, Purvis T, Kilkenny MF, et al; New South Wales Strokes Services Coordinating Commitee; Agency for Clinical Innovation. Evaluation of rural stroke services: does implementation of coordinators and pathways improve care in rural hospitals? Stroke 2013;44:2848-53. DOI PubMed

13. Gardiner FW, Bishop L, Dos Santos A, et al. Aeromedical Retrieval for Stroke in Australia. Cerebrovasc Dis 2020;49:334-40. DOI

14. Cadilhac DA, Kilkenny MF, Longworth M, Pollack MR, Levi CR; Metropolitan Clinical Taskforce and Stroke Services New South Wales Coordinating Committee. Metropolitan-rural divide for stroke outcomes: do stroke units make a difference? Intern Med $J$ 2011;41:321-6. DOI PubMed

15. Gardiner FW, Bishop L, Dos Santos A, et al. Aeromedical retrieval for stroke in Australia. Cerebrovasc Dis 2020;49:334-40. DOI PubMed

16. Prabhakaran S, Ruff I, Bernstein RA. Acute stroke intervention: a systematic review. JAMA 2015;313:1451-62. DOI PubMed

17. Menon BK, Campbell BC, Levi C, Goyal M. Role of imaging in current acute ischemic stroke workflow for endovascular therapy. Stroke 2015;46:1453-61. DOI PubMed

18. Butt A, Jeerakathil T. Equitable access to stroke care in Canada - the geographic conundrum. Can J Neurol Sci 2020;47:285-6. DOI PubMed

19. Eswaradass PV, Swartz RH, Rosen J, Hill MD, Lindsay MP. Access to hyperacute stroke services across Canadian provinces: a geospatial analysis. CMAJ Open 2017;5:E454-9. DOI PubMed PMC

20. Fleet R, Bussières S, Tounkara FK, et al. Rural versus urban academic hospital mortality following stroke in Canada. PLoS One 2018;13:e0191151. DOI PubMed PMC

21. Fleet R, Poitras J, Maltais-Giguère J, Villa J, Archambault P. A descriptive study of access to services in a random sample of Canadian rural emergency departments. BMJ Open 2013;3:e003876. DOI PubMed PMC

22. Gonzales S, Mullen MT, Skolarus L, Thibault DP, Udoeyo U, Willis AW. Progressive rural-urban disparity in acute stroke care. Neurology 2017;88:441-8. DOI PubMed PMC

23. Walter S, Kostpopoulos $\mathrm{P}$, Haass A, et al. Bringing the hospital to the patient: first treatment of stroke patients at the emergency site. PLoS One 2010;5:e13758. DOI PubMed PMC

24. Fassbender K, Walter S, Liu Y, et al. "Mobile stroke unit" for hyperacute stroke treatment. Stroke 2003;34:e44. DOI PubMed

25. Zhao H, Coote S, Easton D, et al. Melbourne mobile stroke unit and reperfusion therapy: greater clinical impact of thrombectomy than thrombolysis. Stroke 2020;51:922-30. DOI PubMed

26. Ebinger M, Kunz A, Wendt M, et al. Effects of golden hour thrombolysis: a prehospital acute neurological treatment and optimization of medical care in stroke (PHANTOM-S) substudy. JAMA Neurol 2015;72:25-30. DOI PubMed

27. Walter S, Kostopoulos P, Haass A, et al. Diagnosis and treatment of patients with stroke in a mobile stroke unit versus in hospital: a randomised controlled trial. Lancet Neurology 2012;11:397-404. DOI PubMed

28. Ebinger M, Siegerink B, Kunz A, et al; Berlin_PRehospital Or Usual Delivery in stroke care (B_PROUD) study group. Association Between Dispatch of Mobile Stroke Units and Functional Outcomes Among Patients With Acute Ischemic Stroke in Berlin. JAMA 2021;325:454-66. DOI PubMed PMC

29. Helwig SA, Ragoschke-Schumm A, Schwindling L, et al. Prehospital stroke management optimized by use of clinical scoring vs mobile stroke unit for triage of patients with stroke: a randomized clinical trial. JAMA Neurol 2019;76:1484-92. DOI PubMed PMC

30. Walter S, Zhao H, Easton D, et al. Air-Mobile Stroke Unit for access to stroke treatment in rural regions. Int J Stroke 2018;13:568-75. DOI PubMed

31. Bladin CF, Kim J, Bagot KL, et al. Improving acute stroke care in regional hospitals: clinical evaluation of the Victorian Stroke Telemedicine program. Med J Aust 2020;212:371-7. DOI PubMed

32. Gardiner F, Gale L, Ransom A, Laverty M. Looking ahead: responding to the health needs of country Australians in 2028 - the centenary year of the RFDS. Canberra: The Royal Flying Doctor Service; 2018.

33. Parker SA, Kus T, Bowry R, et al. Enhanced dispatch and rendezvous doubles the catchment area and number of patients treated on a mobile stroke unit. J Stroke Cerebrovasc Dis 2020;29:104894. DOI PubMed

34. Zhao H, Pesavento L, Coote S, et al. Ambulance clinical triage for acute stroke treatment: paramedic triage algorithm for large vessel occlusion. Stroke 2018;49:945-51. DOI PubMed 
35. Wang Y, Li Z, Zhao X, et al. Stroke care quality in China: Substantial improvement, and a huge challenge and opportunity. Int $J$ Stroke 2017;12:229-35. DOI PubMed

36. Walsh KB. Non-invasive sensor technology for prehospital stroke diagnosis: Current status and future directions. Int J Stroke 2019;14:592-602. DOI PubMed

37. Persson M, Fhager A, Trefná HD, et al. Microwave-based stroke diagnosis making global prehospital thrombolytic treatment possible. IEEE Trans Biomed Eng 2014;61:2806-17. DOI PubMed

38. Available from: https://micro-X.com/products/the-future/. [Last accessed on 23 Feb 2021].

39. Martínez-Sánchez P, Serena J, Alexandrov AV, Fuentes B, Fernández-Domínguez J, Díez-Tejedor E. Update on ultrasound techniques for the diagnosis of cerebral ischemia. Cerebrovasc Dis 2009;27 Suppl 1:9-18. DOI PubMed

40. Available from: https://novasignal.com/solutions/novaguide-intelligent-ultrasound. [Last accessed on 23 Feb 2021].

41. Herzberg M, Boy S, Hölscher T, et al. Prehospital stroke diagnostics based on neurological examination and transcranial ultrasound. Crit Ultrasound J 2014;6:3. DOI PubMed PMC

42. . World Stroke Congress 2020 Abstracts, International Journal of Stroke, 2020, Vol. 15(1S) 3-752. DOI

43. Perry LA, Lucarelli T, Penny-Dimri JC, et al. Glial fibrillary acidic protein for the early diagnosis of intracerebral hemorrhage: Systematic review and meta-analysis of diagnostic test accuracy. Int J Stroke 2019;14:390-9. DOI PubMed

44. Llombart V, García-Berrocoso T, Bustamante A, et al. Plasmatic retinol-binding protein 4 and glial fibrillary acidic protein as biomarkers to differentiate ischemic stroke and intracerebral hemorrhage. J Neurochem 2016;136:416-24. DOI PubMed 